\title{
Alternative splicing and gene polymorphism of the human TAP3/SEC14L4 gene
}

\author{
Petra Kempna $\cdot$ Roberta Ricciarelli • \\ Angelo Azzi $\cdot$ Jean-Marc Zingg
}

Received: 25 March 2009/Accepted: 24 November 2009/Published online: 10 December 2009

(C) Springer Science+Business Media B.V. 2009

\begin{abstract}
Three closely related human SEC14p-like proteins (hTAP1, hTAP2, hTAP3, or SEC14L2, SEC14L3, SEC14L4, respectively) have been described that are related to the Saccharomyces cerevisiae SEC14 protein. These proteins may participate in intracellular lipid transport and influence regulatory lipid-dependent events. Here we report the isolation of an alternatively spliced hTAP3 cDNA and a polymorphism within the coding region of the hTAP3/SEC14L4 gene.
\end{abstract}

Keywords Sec14-like proteins - Tocopherol ·

Phospholipids · Vitamin E · Splicing · Polymorphism

\section{Introduction}

Three human tocopherol associated proteins (hTAP1, hTAP2, hTAP3, also named SEC14L2, SEC14L3, SEC14L4, respectively) have been described [1,2]. Although the three

\section{P. Kempna}

Department of Pediatric Endocrinology and Diabetology,

University Children's Hospital, Bern, Switzerland

R. Ricciarelli

Department of Experimental Medicine, University of Genoa, Genoa, Italy

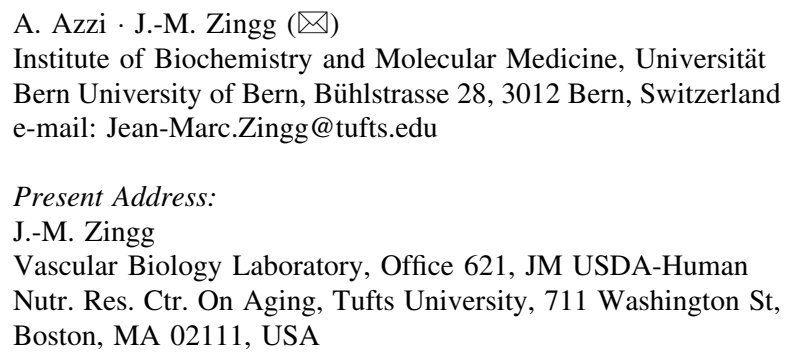

genes are closely related at the nucleic acid and protein sequence (reviewed in [3-5]), they are expressed at different levels in human tissue and exhibit cell specificity within the same organ $[1,6,7]$. Among the tested human tissues, high expression of hTAP3 was seen in the epithelial duct cells of several glands [7]. To date no diseases directly linked to the hTAP genes have been described. However, mutations in related proteins such as PITP, $\alpha$-TTP, CRALBP or ATCAY can lead to hereditary disease, clearly underlying the importance of a correct protein-mediated distribution of hydrophobic molecules [8-12].

The hTAP proteins can recognize phospholipids, squalene, and specific tocopherol analogues and derivatives, suggesting that they may contribute to the cellular uptake, intracellular distribution and secretion of several ligands [1, 13-15]. In addition, the hTAP proteins interact with phosphatidylinositol kinase (PI3K) and possibly modulate the PI3K/PKB signal transduction pathway [1]. This finding was confirmed in prostate tumours in which overexpression of TAP1 increased tocopherol uptake and acted as tumour suppressor by modulating PI3K/PKB activity and cell proliferation $[16,17]$. Tocopherols and phosphatidylinositol compete for binding to hTAPs, suggesting that tocopherols may modulate phospholipid-dependent signalling pathways $[1,14]$. Since the hTAP proteins show a selective binding capacity toward the different natural tocopherols and tocotrienols [15], it can be assumed that these proteins confer specificity by mediating their recognition and selective transport to enzymes, transcription factors, nuclear receptors, organelles such as mitochondria, or specific plasma domains [7].

Here we describe an alternative spliced form of the hTAP3/hSEC14L4 gene and a polymorphism in its coding sequence. The possible role for these hTAP3 variants is discussed. 


\section{Materials and methods}

As previously described, the tissue samples were from transplant donors and had the quality of transplantable material [18]. They were immediately frozen in liquid nitrogen and kept at $-80^{\circ} \mathrm{C}$ if not immediately processed. Total RNA was isolated from tissues using RNAeasy extraction kit (Qiagen). Reverse transcription RT-PCR was performed basically according to the RT-PCR kit from Perkin-Elmer. For detecting the alternatively spliced version of hTAP3 cDNA, a PCR product was obtained by using primers: sense TAP3-Bf (5'-CATGAGCAGCCGAGTC GGG-3 $\left.{ }^{\prime}\right)$ and antisense TAP3-Br (5'-CCATGTGACAAT GTTGTCCAG-3 ${ }^{\prime}$ ). Conditions for PCR were: $95^{\circ}$ for $20 \mathrm{~s}$, $62^{\circ}$ for $20 \mathrm{~s}, 72^{\circ}$ for $20 \mathrm{~s}$, for 35 cycles, using Hot Star Polymerase. Screening for the $16 \mathrm{bp}$ insertion included reverse transcription followed by PCR amplification of a short 223 bp fragment (239 bp with the insertion), purification, gel extraction and cleavage by BamHI. Expected sizes:

Normal PCR product : $223 \mathrm{bp}$

$$
\begin{aligned}
& \Downarrow \text { cut with BamHI } \\
& 223 \text { bp }
\end{aligned}
$$

PCR product $+16 \mathrm{bp}$ insert : $239 \mathrm{bp}$

$$
\begin{aligned}
& \Downarrow \text { cut with BamHI } \\
& 175 \mathrm{bp}+56 \mathrm{bp}
\end{aligned}
$$

For detecting the PstI polymorphism, a region potentially containing the PstI site was amplified by using primer hTAP3afw (5'-CATGAGCAGCCGAGTCGGG-3') and hTAP3arv (5'-GGGCTCGAATAACAATTAAATT-3'). Conditions for PCR were as follows: $95^{\circ} \mathrm{C}, 30 \mathrm{~s} ; 55^{\circ} \mathrm{C}, 30 \mathrm{~s}$; and $72^{\circ} \mathrm{C}, 1 \mathrm{~min}$, for 35 cycles. PCR products of $580 \mathrm{bp}$ size were purified by gel extraction and the presence of the PstI restriction site determined by enzymatic cleavage with PstI. Direct sequencing of hTAP3 clones was performed by Microsynth (Balgach, Switzerland).

\section{Results and discussion}

During sequencing of the hTAP3 (or hSEC14L4) cDNA [1], two mutations were detected: the insertion of a short $16 \mathrm{bp}$ fragment at position +55 (Fig. 1a), and a silent point mutation at position +409 of the coding sequence (Fig. 1b). Both changes are leading to the formation of new and unique restriction sites; the $16 \mathrm{bp}$ insertion contained a unique BamHI restriction site, whereas the silent point mutation generated a unique PstI restriction site. This allowed the application of a fast screening method consisting of PCR-mediated amplification of a short region of the hTAP3 cDNA, followed by restriction fragment length analysis (see methods).

Because hTAP3 is not expressed in cell lines [7], total RNA isolated from human tissues was used to screen for the presence of the hTAP3 gene variants. The analysis performed on different tissues from seven different donors indicated that the majority of the samples express about equal amounts of hTAP3 with and without the $16 \mathrm{bp}$ insertion derived from alternative splicing (Fig. 2; Table 1). At this time, no firm statement can be made about relative expression levels of the two alternatively spliced forms, since cells in a tissue could either express both forms in each cell, or one cell type in a tissue may express one form and another cell type the other. However, donor 1 contains only the correctly spliced version of hTAP 3 in both liver and skin, possibly indicating that alternative

\begin{abstract}
(A) hTAP3 cDNA sequence +1 - + 138
ATGAGCAGCCGAGTCGGGGACCTGAGCCCCCAGCAGCAGGAAGCGCTGGCCAGG - . . . . . . . . . . . ATGAGCAGCCGAGTCGGGGACCTGAGCCCCCAGCAGCAGGAAGCGCTGGCCAGGATCCTCCTCCGCTCAG Bam HI TTCCGGGAGAACCTCCAGGACCTGCTGCCCATACTGCCCAATGCTGATGACTACTTCCTCCTGCGCTG TTCCGGGAGAACCTCCAGGACCTGCTGCCCATACTGCCCAATGCTGATGACTACTTCCTCCTGCGCTG
\end{abstract}

(B) hTAP3 cDNA sequence +376 - +444 AAAGTCTGTGAGCTGCTGTTGCATGAGTGTGAGCTGCAAACTCAGAAGCTGGGCAGGAAGATCGAGATG AAAGTCTGTGAGCTGCTGTTGCATGAGTGTGAGCTGCAGACTCAGAAGCTGGGCAGGAAGATCGAGATG

Fig. 1 Polymorphism and alternative splicing of the human SEC14L4 gene. a Two versions of hTAP3 cDNA sequences detected during amplification and cloning of hTAP3 cDNA. The insertion of $16 \mathrm{bp}$ (grey shading) originated from the first intron at position +55 by alternative splicing, generating a new, unique BamHI restriction site (GGATCC, underlined). So far, a new protein product related to this insertion was not identified, most likely because the insertion of $16 \mathrm{bp}$ results in a shift of the open reading frame, generating truncated proteins stopping at alternative stop codons unless an alternative start codon is used. Start (ATG) and stop codons (TGA) are indicated in bold. The sequence of the PCR fragment containing the alternatively spliced hTAP3 mRNA has been submitted to Genbank (accession number FJ824055). b Mutation in one base at position $+414(\mathrm{~A} \rightarrow \mathrm{G}$, bold $)$ (or as reverse complement, $\mathrm{C} \rightarrow \mathrm{T}$ ) generates a new restriction site (PstI, underlined) which is present also in the hTAP2 cDNA. Mutation itself does not change the amino acid (Gly $\rightarrow$ Gly), but might be linked with other mutations. This mutation corresponds to the $\mathrm{C} / \mathrm{T}$ small nucleotide polymorphism (dbSNP:9606738), which is described at http://www.ncbi.nlm.nih. gov/SNP/snp_ref.cgi?type=rs\&rs=9606738 


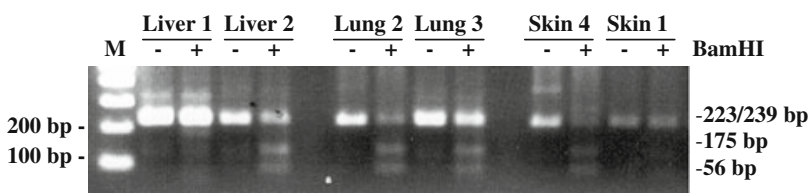

Fig. 2 Screening for the alternatively spliced human SEC14L4 mRNA. Screening was performed as described in methods. Two aliquots of each sample-one cut with BamHI $(+)$ and one uncut $(-)$-were separated by a $2.5 \%$ agarose gel, visualized with ethidium bromide, scanned and analysed using a Lumimager. Samples from different individuals are labelled 1, 2, 3, and 4. In all samples two variants of hTAP3 gene are detectable, with exception of donor 1 , where a BamHI cleaved alternatively spliced form was not observed in liver and in skin

splicing occurs in a regulated manner, or as a consequence of additional changes that influence it in a tissue and/or individual specific manner. This may be the result of alterations in the splicing consensus sequence or the splicing machinery, although no polymorphisms have been so far described within intron 1 (http://www.ncbi.nlm.nih. gov/SNP/snp_ref.cgi?locusId=284904). Sequence analysis of the exon-intron junction between exon 1 and 2 revealed that the additional $16 \mathrm{bp}$ in the alternatively spliced hTAP 3 cDNA come from alternative usage of the $3^{\prime}$-splicing junction of intron 1 (Fig. 3a). Alignment of the three closely related hTAP sequences (hTAP1, hTAP2, hTAP3) showed that the $3^{\prime}$-splice junction of hTAP3 in intron 1 is shifted by 4 nucleotides possibly allowing the usage of two alternative splicing sites (Fig. 3b). Interspecies sequence alignment of the intron 1-exon 2 junction of hTAP3 revealed that the alternative $3^{\prime}$-splice junction is present in humans, chimpanzee, and rhesus monkeys, but not in mouse or rabbits, possibly indicating that alternative splicing of hTAP3 evolved only in higher primates (Fig. 3c).

The hTAP3 cDNAs from three of four tested donors contain a PstI restriction site (Table 1). The PstI polymorphism (dbSNP:9606738) has been described to occur at different frequency in different ethnic groups (Table 2) (http://www.ncbi.nlm.nih.gov/SNP/snp_ref.cgi?type=rs\& rs=9606738). In the sequences so far analyzed, the $\mathrm{C} / \mathrm{C}$ genotype (PstI site present in both alleles) occurs mainly in the European, the $\mathrm{C} / \mathrm{T}$ genotype (PstI site present in one allele) in the European and African, and the T/T genotype (PstI site absent in both alleles) in the Asian population.

At this time it is not possible to estimate the importance of the here described hTAP3 gene variants, because until now research has mainly focused on hTAP1 and establishing a link with certain diseases requires a better understanding of the three closely related hTAP proteins. The three hTAP proteins may participate in intracellular lipid transport and consequently influence lipid metabolism as well as lipid-dependent events, including signal transduction, gene expression and secretion.

We and others have found that hTAP proteins can modulate phosphatidylinositol-3-kinase (PI3K) in vitro $[1,16]$; other enzymes such as phosphatidylinositol-4-kinase (PI4K), phospholipases, squalene epoxidase, fatty acid synthase, and choline-phosphate cytidyltransferases may be modulated by hTAPs as well. A role for TAP proteins in the biosynthesis of cholesterol was firstly suggested by the identification of TAP1/SEC14L2 as the previously described microsomal supernatant protein factor (SPF) [19]. SPF/ TAP1/SEC14L2 stimulates squalene epoxidation, a reaction required for cholesterol synthesis, either by directly stimulating squalene transport to the enzyme or possibly by increasing the transport and generation of vesicles carrying squalene $[19,20]$. As shown with TAP1/SPF-knockout mice, SPF/TAP1/SEC14L2 maintains the steady-state plasma cholesterol level during fasting by compensating for decreased squalene epoxidase and HMG-CoA reductase activity [21].

Modulation of PI3K by hTAPs may also affect gene expression in a tocopherol-dependent manner, e.g. by affecting the PI3K/PKB/PPAR $\gamma$ signal transduction pathway. Indeed, the involvement of TAP1 in the modulation of gene expression has been recently described; mouse TAP1 was found to stimulate the expression of the mast cell proteases genes mmcp-1 and mmcp-7, whereas the expression of TAP1 itself can be up-regulated by activin/ TGF- $\beta$ treatment during differentiation of bone-marrow

Table 1 Occurrence of alternative splicing of hTAP3 in different tissues of seven individuals as detected using the newly generated BamHI restriction site

\begin{tabular}{|c|c|c|c|c|c|c|c|c|}
\hline & Sample 1 & Sample 2 & Sample 3 & Sample 4 & Sample 5 & Sample 6 & Sample 7 & Tissue \\
\hline PstI polymorphism positive & + & + & + & - & & & & \\
\hline \multirow[t]{6}{*}{ BamHI positive (alternative splicing present) } & & + & + & & & & & Lung \\
\hline & - & + & & & & & & Liver \\
\hline & & + & + & + & & & & Muscle \\
\hline & - & & & + & & & & Skin \\
\hline & & & & & - & & - & Adrenal \\
\hline & & & & & & + & & Placenta \\
\hline
\end{tabular}


(A) hTAP3 genomic sequence exon 1, intron 1 and part of exon 2

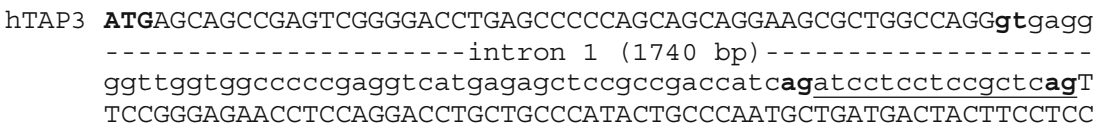

(B) Alignment of intron 1 - exon 2 junction of hTAP1, hTAP2 and hTAP3

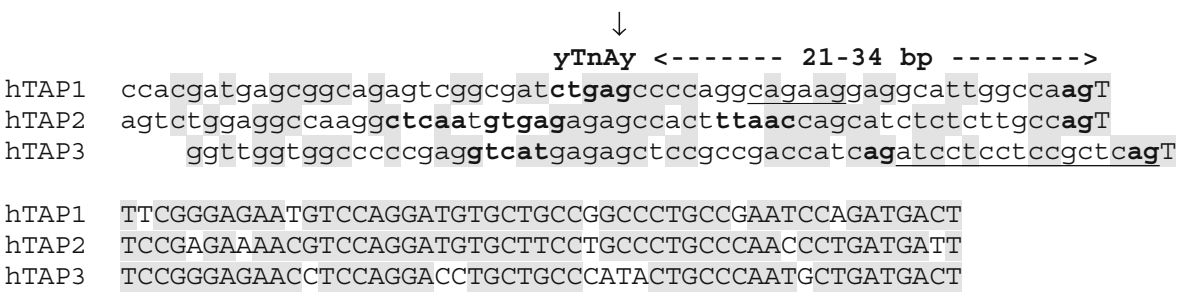

(C) Interspecies alignment of intron 1 - exon 2 junction of TAP3

\begin{tabular}{|c|c|}
\hline & \\
\hline & traqaq \\
\hline & ccaaggtcatgagagttccgcts \\
\hline & agatgaccaggaacactctgacc \\
\hline & agatgaccaggaacactctgatta \\
\hline & \\
\hline & СCTGCTG \\
\hline & ACCTCCAGAACCTGCTGCCCATGCTGCCCAATGCTGATC \\
\hline & CAGGATCTGCTGCCCACCCTGCCCAAGGCCGATG: \\
\hline & \\
\hline
\end{tabular}

Fig. 3 Alternative splicing of hTAP3 intron 1. a Alternative usage of the $3^{\prime}$-splice junction of hTAP3. Shown is the genomic sequence of exon 1, intron 1 and start of exon 2 of the hTAP3 gene. Start of protein (ATG, bold), intronic $5^{\prime}$ - and $3^{\prime}$-junctions (bold), inserted sequence after alternative splicing (underlined). Exons (upper case), intron (lower case). b Alignment of the intron 1 - exon 2 junctions of hTAP1, hTAP2, and hTAP3. The conserved dinucleotides ag of the $3^{\prime}$-splice junctions are shown in bold, the nucleotides conserved in two of the three genes in grey shading, the most likely splicing branch point adenine in hTAP1 is marked by an arrow. Homologies to the human branch point consensus sequence yTnAy are shown in bold [34]. In hTAP3, the distance of the $3^{\prime}$-splice junction to the branch point is longer, possibly explaining the usage of an additional $3^{\prime}$ splice junction in hTAP3. Intron (lower case), exon (upper case). c Alignment of the intron 1 -exon 2 junctions of TAP3 from Homo sapiens (hTAP3), Macaca mulatta (mmTAP3), Pan troglodytes (ptTAP3), Mus musculus (mTAP3) and Rattus norvegicus (rTAP3). Homologies to the human branch point consensus sequence yTnAy are shown in bold [34]. The most likely branch point and alternative splicing junction are conserved in primates, but not in rodents

Table 2 Occurrence of PstI polymorphism in the population

\begin{tabular}{|c|c|c|c|c|c|c|c|}
\hline Population & ss\# & \# Samples & $\mathrm{C} / \mathrm{C}$ & $\mathrm{C} / \mathrm{T}$ & $\mathrm{T} / \mathrm{T}$ & $\mathrm{C}$ & $\mathrm{T}$ \\
\hline European & ss 23630390 & 48 & 0.083 & 0.250 & 0.667 & 0.208 & 0.792 \\
\hline African-American & ss 23630390 & 46 & 0.000 & 0.478 & 0.522 & 0.239 & 0.761 \\
\hline Asian & ss 23630390 & 48 & 0.000 & 0.000 & 1.000 & 0.000 & 1.000 \\
\hline European & ss 48402672 & 120 & 0.033 & 0.417 & 0.550 & 0.242 & 0.758 \\
\hline Asian & ss 48402672 & 90 & 0.000 & 0.067 & 0.933 & 0.033 & 0.967 \\
\hline Asian & ss 48402672 & 88 & 0.000 & 0.023 & 0.977 & 0.011 & 0.989 \\
\hline Sub-Saharan African & ss 48402672 & 120 & 0.000 & 0.133 & 0.867 & 0.067 & 0.933 \\
\hline Multiple & ss 48402672 & 56 & 0.036 & 0.143 & 0.821 & 0.107 & 0.893 \\
\hline
\end{tabular}

derived mast cells $[22,23]$. The expression of hTAP1 is upregulated during primary mast cell differentiation, indicating a role of this protein in cells of the native immune system [7]. Expression of TAP2 is inversely correlated with allergic airway inflammation [24].

hTAP1 and hTAP2 are expressed, although at a low level, in several cell lines, whereas hTAP3 expression is undetectable in so far all tested cell lines; interestingly, in primary cells and tissues the three hTAP proteins appear to be more abundant [7]. These results suggest that the hTAP proteins may be expressed in the fully differentiated state or interfere with proliferation, possibly becoming downregulated during cell line expansion and/or tumor promotion $[16,25]$. Accordingly, previous results suggested that 
epigenetic changes are at the basis of hTAP1 gene silencing in cancer cells, since treatment with demethylating agents can recover TAP expression [7, 16]. Moreover, overexpression of hTAP1 in mesothelioma cells renders them more sensitive to $\alpha$-tocopheryl succinate, again suggesting that hTAP down-regulation may serve to escape the apoptotic effects of this anti-proliferative compound [26]. In line with this, proliferation of prostate cancer cells correlates with a reduced expression of hTAP1 $[16,17]$ whereas certain small nucleotide polymorphisms (SNP) in the hTAP1 gene are associated with an increased risk for prostate cancer $[27,28]$. Moreover, lower levels of hTAP1 have been detected in breast cancer [25, 29].

hTAP3/SEC14L4 is predominantly expressed in epithelial duct cells of several glands (e.g. salivary gland, prostate, pancreas, mammary gland), suggesting that it may be involved in polarized secretion from these cells [7]. Accordingly, the related Saccharomyes cerevisiae SEC14p mediates vesicle formation and secretion from endosomes and trans-Golgi network possibly through activation of PI4K [30-32]. Alternatively, the hTAP function may have shifted from lipid transfer to enzymes to lipid insertion into secretory vesicles, organelles or specific plasma domains.

In conclusion, the here detected gene polymorphism could be used as a chromosomal linkage marker, e.g. to establish a correlation between ethnic differences seen in incidences of diseases and specific hTAP3 gene variants. The presence of the alternatively spliced form could lead to reduced levels of functional hTAP3 protein expression what may not necessarily lead to a disease, but may play a role in determining inter-individual differences in the secretory and/or proliferative capability of epithelial duct cells [7], alter the risk for certain diseases and possibly influence the disease-preventive effects of vitamin $\mathrm{E}$ in supplementation studies [33].

A further analysis of the biological relevance of the here described hTAP3 variants requires the definite assignment of the wild type hTAP3 function. Future studies should address the molecular role of these hTAP3 variants and their pattern of expression in normal and pathological tissues, possibly with single cell resolution to reveal cell type specific splicing patterns.

Acknowledgments This work was supported by the Swiss National Science Foundation.

\section{References}

1. Kempna P, Zingg JM, Ricciarelli R, Hierl M, Saxena S, Azzi A (2003) Cloning of novel human SEC14p-like proteins: ligand binding and functional properties. Free Radic Biol Med 34:1458-1472

2. Ye X, Ji C, Yin G, Tang R, Zeng L, Gu S, Ying K, Xie Y, Zhao RC, Mao Y (2004) Characterization of a human Sec14-like protein cDNA SEC14L3 highly homologous to human SPF/TAP. Mol Biol Rep 31:59-63

3. Mousley CJ, Tyeryar KR, Vincent-Pope P, Bankaitis VA (2007) The Sec14-superfamily and the regulatory interface between phospholipid metabolism and membrane trafficking. Biochim Biophys Acta 1771:727-736

4. Bankaitis VA, Vincent P, Merkulova M, Tyeryar K, Liu Y (2007) Phosphatidylinositol transfer proteins and functional specification of lipid signaling pools. Adv Enzyme Regul 47:27-40

5. Saito K, Tautz L, Mustelin T (2007) The lipid-binding SEC14 domain. Biochim Biophys Acta 1771:719-726

6. Zimmer S, Stocker A, Sarbolouki MN, Spycher SE, Sassoon J, Azzi A (2000) A novel human tocopherol-associated protein: cloning, in vitro expression, and characterization. J Biol Chem 275:25672-25680

7. Zingg JM, Kempna P, Paris M, Reiter E, Villacorta L, Cipollone R, Munteanu A, De Pascale C, Menini S, Cueff A, Arock M, Azzi A, Ricciarelli R (2008) Characterization of three human sec14plike proteins: alpha-tocopherol transport activity and expression pattern in tissues. Biochimie 90(11-12):1703-1715

8. Milligan SC, Alb JG, Elagina RB, Bankaitis VA, Hyde DR (1997) The phosphatidylinositol transfer protein domain of Drosophila retinal degeneration B protein is essential for photoreceptor cell survival and recovery from light stimulation. J Cell Biol 139:351-363

9. Hamilton BA, Smith DJ, Mueller KL, Kerrebrock AW, Bronson RT, van Berkel V, Daly MJ, Kruglyak L, Reeve MP, Nemhauser JL, Hawkins TL, Rubin EM, Lander ES (1997) The vibrator mutation causes neurodegeneration via reduced expression of PITP alpha: positional complementation cloning and extragenic suppression. Neuron 18:711-722

10. Maw MA, Kennedy B, Knight A, Bridges R, Roth KE, Mani EJ, Mukkadan JK, Nancarrow D, Crabb JW, Denton MJ (1997) Mutation of the gene encoding cellular retinaldehyde-binding protein in autosomal recessive retinitis pigmentosa. Nat Genet 17:198-200

11. Yokota T, Uchihara T, Kumagai J, Shiojiri T, Pang JJ, Arita M, Arai H, Hayashi M, Kiyosawa M, Okeda R, Mizusawa H (2000) Postmortem study of ataxia with retinitis pigmentosa by mutation of the alpha-tocopherol transfer protein gene. J Neurol Neurosurg Psychiatry 68:521-525

12. Bomar JM, Benke PJ, Slattery EL, Puttagunta R, Taylor LP, Seong E, Nystuen A, Chen W, Albin RL, Patel PD, Kittles RA, Sheffield VC, Burmeister M (2003) Mutations in a novel gene encoding a CRAL-TRIO domain cause human Cayman ataxia and ataxia/dystonia in the jittery mouse. Nat Genet 35:264-269

13. Kempna P, Cipollone R, Villacorta L, Ricciarelli R, Zingg JM(2003) Isoelectric point mobility shift assay for rapid screening of charged and uncharged ligands bound to proteins. IUBMB Life 55:103-107

14. Habermehl D, Kempna P, Azzi A, Zingg JM (2005) Recombinant SEC14-like proteins (TAP) possess GTPase activity. Biochem Biophys Res Commun 326:254-259

15. Panagabko C, Morley S, Hernandez M, Cassolato P, Gordon H, Parsons R, Manor D, Atkinson J (2003) Ligand specificity in the CRAL-TRIO protein family. Biochemistry 42:6467-6474

16. Ni J, Wen X, Yao J, Chang HC, Yin Y, Zhang M, Xie S, Chen M, Simons B, Chang P, di Sant'agnese A, Messing EM, Yeh S (2005) Tocopherol-associated protein suppresses prostate cancer cell growth by inhibition of the phosphoinositide 3-kinase pathway. Cancer Res 65:9807-9816

17. Wen XQ, Li XJ, Su ZL, Liu Y, Zhou XF, Cai YB, Huang WT, Gao X (2007) Reduced expression of alpha-tocopherol-associated protein is associated with tumor cell proliferation and the increased risk of prostate cancer recurrence. Asian J Androl 9:206-212

18. Zingg JM, Ricciarelli R, Andorno E, Azzi A (2002) Novel 5, exon of scavenger receptor CD36 is expressed in cultured human 
vascular smooth muscle cells and atherosclerotic plaques. Arterioscler Thromb Vasc Biol 22:412-417

19. Shibata N, Arita M, Misaki Y, Dohmae N, Takio K, Ono T, Inoue K, Arai H (2001) Supernatant protein factor, which stimulates the conversion of squalene to lanosterol, is a cytosolic squalene transfer protein and enhances cholesterol biosynthesis. Proc Natl Acad Sci USA 98:2244-2249

20. Mokashi V, Singh DK, Porter TD (2005) Supernatant protein factor stimulates HMG-CoA reductase in cell culture and in vitro. Arch Biochem Biophys 433:474-480

21. Shibata N, Jishage K, Arita M, Watanabe M, Kawase Y, Nishikawa K, Natori Y, Inoue H, Shimano H, Yamada N, Tsujimoto M, Arai H (2006) Regulation of hepatic cholesterol synthesis by a novel protein (SPF) that accelerates cholesterol biosynthesis. Faseb J 20:2642-2644

22. Yamauchi J, Iwamoto T, Kida S, Masushige S, Yamada K, Esashi $\mathrm{T}$ (2001) Tocopherol-associated protein is a ligand-dependent transcriptional activator. Biochem Biophys Res Commun 285:295-299

23. Funaba M, Murakami M, Ikeda T, Ogawa K, Tsuchida K, Sugino $\mathrm{H}$ (2006) Identification of tocopherol-associated protein as an activin/TGF-beta-inducible gene in mast cells. Biochim Biophys Acta 1763:900-906

24. Shan L, Kawakami T, Asano S, Noritake S, Yoshimoto D, Yamashita K, Kikkawa H, Kinoshita M, Matsubara S (2009) Inverse relationship between Sec1413 mRNA/protein expression and allergic airway inflammation. Eur J Pharmacol 616(1-3):293-300

25. Johnykutty S, Tang P, Zhao H, Hicks DG, Yeh S, Wang X (2009) Dual expression of alpha-tocopherol-associated protein and estrogen receptor in normal/benign human breast luminal cells and the downregulation of alpha-tocopherol-associated protein in estrogen-receptor-positive breast carcinomas. Mod Pathol 22(6):770-775

26. Neuzil J, Dong LF, Wang XF, Zingg JM (2006) Tocopherolassociated protein-1 accelerates apoptosis induced by alpha- tocopheryl succinate in mesothelioma cells. Biochem Biophys Res Commun 343:1113-1117

27. Wright ME, Peters U, Gunter MJ, Moore SC, Lawson KA, Yeager M, Weinstein SJ, Snyder K, Virtamo J, Albanes D (2009) Association of variants in two vitamin e transport genes with circulating vitamin e concentrations and prostate cancer risk. Cancer Res 69(4):1429-1438

28. Zingg JM, Azzi A (2009) Comment re: Vitamin E transport gene variants and prostate cancer. Cancer Res 69(16):6756; author reply 6756

29. Wang X, Ni J, Hsu CL, Johnykutty S, Tang P, Ho YS, Lee CH, Yeh S (2009) Reduced expression of tocopherol-associated protein (TAP/Sec14L2) in human breast cancer. Cancer Investig 27(10):971-977

30. Schaaf G, Ortlund EA, Tyeryar KR, Mousley CJ, Ile KE, Garrett TA, Ren J, Woolls MJ, Raetz CR, Redinbo MR, Bankaitis VA (2008) Functional anatomy of phospholipid binding and regulation of phosphoinositide homeostasis by proteins of the sec14 superfamily. Mol Cell 29(2):191-206

31. Curwin AJ, Fairn GD, McMaster CR (2009) Phospholipid transfer protein Sec14 is required for trafficking from endosomes and regulates distinct trans-Golgi export pathways. J Biol Chem 284(11):7364-7375

32. Schaaf G, Betts L, Garrett TA, Raetz CR, Bankaitis VA (2006) Crystallization and preliminary $\mathrm{X}$-ray diffraction analysis of phospholipid-bound Sfh1p, a member of the Saccharomyces cerevisiae Sec14p-like phosphatidylinositol transfer protein family. Acta Crystallogr Sect F Struct Biol Cryst Commun 62:1156-1160

33. Zingg JM, Azzi A, Meydani M (2008) Genetic polymorphisms as determinants for disease-preventive effects of vitamin E. Nutr Rev 66(7):406-414

34. Gao K, Masuda A, Matsuura T, Ohno K (2008) Human branch point consensus sequence is yUnAy. Nucleic Acids Res 36(7):2257-2267 